\title{
Expansión ganadera en la Sierra de Santa Marta, Veracruz: el caso de una comunidad zoque-popoluca
}

\author{
The Expansion of Cattle-Ranching in the Sierra de Santa Marta, Veracruz: \\ the Case of a Zoque-Popoluca Community
}

José Manuel Flores López

UNIVERSIDAD ESTADUAL DE CAMPINAS, UNICAMP, CAMPINAS, SÃO PAULO, BRASIL,

floreslopezjm@hotmail.com

El artículo describe el proceso de ganaderización, iniciado a comienzos de la década de 1980, de una pequeña comunidad zoque-popoluca del sur del estado de Veracruz. Los principales mecanismos mediante los cuales se adoptó la actividad ganadera fueron los tratos productivos conocidos como ganado "a medias" y "renta de pastos". Este proceso de ganaderización tuvo impactos profundos en la transformación de las actividades económicas locales y del paisaje, un proceso regional en el cual tuvieron importancia los grandes procesos nacionales como el impulso a la actividad ganadera como forma de expansión hacia las zonas tropicales del país, así como las políticas de colonización y de reparto agrario.

PaLABRAS ClaVE: Sierra de Santa Marta, indígenas zoques-popolucas, ganaderización, ganado a medias, renta de pastos.

This article describes the process of the expansion of cattle-ranching that began in the early 1980s, affecting a small Zoque-Popoluca community in southern Veracruz state. The principle vehicles through which livestock-raising activity came to be implemented were sharecropping-like production agreements (a medias) and the leasing of pasturelands. This process of expanding livestock-raising had profound impacts as it transformed both local economic activities and the physical landscape. This was a regional process in which broad national initiatives like fomenting the spread of cattle production into the tropical zones of the country played an important role, together with settlement policies and agrarian reform.

KeYwords: Sierra de Santa Marta, Zoque-Popoluca indigenous peoples, expansion of cattle-ranching, shared herds, leasing of pasturelands.

Fecha de recepción del artículo: 17 de septiembre de 2013 / Fecha de aprobación: 28 de enero de 2014 / Fecha de recepción de la versión final: 22 de mayo de 2014. 
A la memoria de François Lartige

\section{INTRODUCCIÓN}

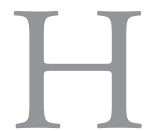

uyendo de la violencia que desencadenó en 1906 un movimiento armado dirigido por líderes magonistas radicados en las ciudades de Coatzacoalcos, Minatitlán y Acayucan, varias familias zoques-popolucas, procedentes principalmente del municipio de San Pedro Soteapan, se internaron en la montaña para establecerse allí definitivamente. En el lugar al que llegaron encontraron una gran roca alargada, uno de cuyos costados estaba marcado con signos extrańos que le daban la apariencia "como de un hombre" o bien como de "una espiga", según dicen hoy algunos hombres que jamás la han visto pero que saben de ello por lo que sus padres y abuelos les contaron. El hallazgo de esta gran roca, labrada y erigida como monumento más de mil ańos atrás por una cultura y sociedad completamente diferentes a las de ellos, marca el inicio de la existencia de una pequeña comunidad popoluca en medio de la selva. La piedra llenó con significación la vida de sus pobladores, tal vez anunciando nuevos y mejores tiempos, y de ella tomaron su nombre, Piedra Labrada, quedando así desde el principio inextricablemente unida a la identidad colectiva. Pero, sobre todo, al otorgarle la capacidad de regular la existencia de maíz en las milpas, fue considerada como la fuente que posibilitó su misma existencia como un pueblo agricultor en la selva. Hoy en día, sin embargo, las personas que se dedican al campo ya casi no cultivan la tierra y algunos viejos "lloran el maíz". Ahora son ganaderos. Milpas y montañas han quedado atrás como elementos predominantes en el paisaje y sus lugares han sido ocupados por pastos y alambres de púas.

La transformación de las estrategias económicas de los habitantes de Piedra Labrada, su conversión de agricultores a ganaderos, tuvo lugar en una década. A comienzos de los ochenta del siglo pasado, la mayoría de las familias se dedicaban a la agricultura. A mediados de los noventa, las milpas ya eran extrańas en el paisaje dominado por verdes lomeríos. Este cambio, generalizado en toda la región, aunque con ritmos diferentes, supuso una pérdida importante de la cu- 
bierta vegetal selvática, ahora reducida a unos cuantos acahuales y a las cercas vivas que dividen los potreros. El hecho resulta algo desconcertante si se considera que Piedra Labrada se encuentra ubicada, como muchos otros ejidos vecinos que han experimentado procesos similares, en una zona que ha sido, precisamente desde comienzos de la década de 1980, el objetivo de diversos programas de conservación ambiental.

Este texto tiene como propósito describir el proceso mediante el cual la comunidad de Piedra Labrada fue absorbida por la actividad ganadera a partir de los ochenta, lo cual implicó una profunda transformación del paisaje y de las actividades económicas locales. A este desarrollo contribuyó una interrelación de distintos factores, convergiendo en esta historia grandes procesos nacionales como el impulso a la actividad ganadera como forma de expansión hacia las zonas tropicales del país; las políticas de colonización y de reparto agrario; también las dinámicas políticas regionales, así como las propias circunstancias económicas de los pobladores de Piedra Labrada que, a través de los tratos productivos conocidos como ganado "a medias" y "renta de pastos", encontraron en la actividad ganadera una estrategia viable para ganarse la vida, aun a expensas de la agricultura y de la cubierta vegetal selvática hoy casi extinta.

Piedra Labrada se localiza en el municipio de Tatahuicapan, en la región conocida como Sierra de Santa Marta, en el sur de Veracruz, que constituye un espacio interétnico habitado principalmente por indígenas nahuas y popolucas y al que se han integrado mestizos provenientes de otros municipios del estado de Veracruz así como de otros estados del país. La Sierra de Santa Marta forma parte de una región natural más amplia conocida como Los Tuxtlas, caracterizada por una biodiversidad única, aunque en la actualidad sea, en su mayor parte, un inmenso potrero para la cría de ganado vacuno.

Piedra Labrada tiene 512 habitantes. La actividad económica predominante, como en muchos otros lugares de la región, es la pequeña ganadería de doble propósito, aunque algunos siguen practicando el cultivo del maíz, sobre todo, en el ciclo primavera verano. La migración temporal, principalmente de jóvenes, ha cobrado importancia en los últimos quince años. Los destinos principales son 
Oaxaca, donde asisten al corte de limón; los campos de tomate de Sinaloa; y las fábricas y maquilas de Ciudad Juárez, Chihuahua; y de Ciudad Acuńa, Coahuila. Una característica sociocultural de los pueblos de esta parte de la Sierra es que en su mayoría no son católicos. Gran parte de la población se convirtió al protestantismo hace más de cincuenta años; en la actualidad en Piedra Labrada hay varios templos evangélicos y pentecostales. La vecina Úrsulo Galván, comunidad habitada por mestizos provenientes de Los Tuxtlas, es una de las pocas comunidades habitadas por católicos. Con la excepción del lenguaje, los signos más evidentes que vinculan a un individuo con cierto grupo cultural, como el vestido, han desaparecido o se han trasformado. En las últimas dos décadas, los pobladores de Piedra Labrada también han tenido que enfrentar otras transformaciones importantes como la pérdida de la mitad de las tierras ejidales en manos de rancheros externos, lo cual ha implicado profundas transformaciones en la organización sociocultural.

\section{El paisaje de la Sierra}

La selva de Los Tuxtlas, región natural de la cual la Sierra de Santa Marta forma parte, es la más septentrional del continente. Más allá no existen ecosistemas con las características propias de la selva alta húmeda americana. Del inmenso mar verde que una vez fue, hoy sólo quedan pocos remanentes, menos de $15 \%$ de la cubierta forestal original (véase Guervara y otros 2004; Paré y otros 1997). Algunos de estos remanentes aún están lo suficientemente compactos como para apenas afirmar la existencia de una selva tropical. La cubierta vegetal que ha logrado escapar a la actividad productiva rehuye, arrinconándose en las cimas de los volcanes y sus laderas más abruptas, donde la selva se apretuja con otros tipos de vegetación como el bosque mesófilo de montańa o los bosques de pinos y encinos.

Una "isla" ha sido, no sin razón, metáfora pertinente para referirse a Los Tuxtlas. ${ }^{1} \mathrm{La}$ Sierra es un gran macizo de origen volcánico

${ }^{1}$ La descripción sobre la diversidad ecológica la realizo principalmente a partir de los artículos presentados por Sergio Guevara S., Javier Laborde y Graciela Sánchez (2004). También puede consultarse una buena descripción al respecto en Ramírez (1999). 
que se levanta rompiendo bruscamente con las suaves planicies costeras del Golfo de México. Si uno recurre a un mapa aéreo, o mejor aún, a una fotografía satelital en la que con colores distinga las diferentes características topográficas, geológicas y forestales, se podrá observar que la Sierra, incrustada directamente sobre la masa continental, se encuentra aislada de cualquier otro sistema montańoso. En esa misma fotografía destacarán enseguida tres elevaciones cónicas: en un eje que va de norte a sureste, los volcanes San Martín Tuxtla (1,650 msnm), Santa Marta (1,700 msnm) y San Martín Pajapan (1,200 msnm); y una enorme laguna entre la primera y las dos últimas: la de Catemaco. Dos lagunas más, formadas al igual que la de Catemaco por la obstrucción costera causada por las erupciones, aunque de menor tamaño, llaman la atención: Sontecomapan, al norte de Catemaco y la Laguna del Ostión, hacia el sureste y sobre la costa, marcando el final de la Sierra.

Los efectos de la actividad volcánica son evidentes en toda la Sierra. Los lomeríos, formados por las deposiciones de cenizas y otros materiales son el paisaje dominante; se extienden por toda el área, ocupando más de $80 \%$ de ella. El resto del relieve de la Sierra lo ocupan las elevaciones volcánicas mayores y, en menor medida, las planicies. Los materiales volcánicos dieron también forma a la red fluvial. De la cima de cada uno de los volcanes surge una red de ríos que vista desde arriba asemeja a una telarańa cuyas puntas se extienden sobre el territorio desde un centro hacia todas direcciones. Esta red de drenaje radial que se origina en las elevaciones volcánicas es alimentada por la copiosa lluvia anual. La Sierra es una de las cinco regiones más lluviosas del país. Anualmente recibe 4,000 mm/año. Ningún otro lugar en el Golfo de México, desde Florida hasta Campeche, recibe anualmente una precipitación pluvial más alta. Los numerosos ríos que descienden de las montańas drenan en alguna de las dos cuencas a las que está ligada: la del Papaloapan, al norte; y el Coatzacoalcos, al sureste; y de ahí hacia el Golfo de México o, bien, lo hacen directamente en el mar. Ciudades como Coatzacoalcos, Minatitlán y Cosoleacaque, localizadas en las llanuras bajas e inundables en el sureste y sometidas a un rápido proceso de concentración industrial y de contaminación, son abastecidas con 
las aguas del río Texizapan que nace en la Sierra y que han sido utilizadas con éxito como arma política por los habitantes campesinos de Tatahuicapan.

Diferencias altitudinales y lo accidentado del relieve de la Sierra van de la mano con una diversidad de microclimas o subtipos climáticos en los que predominan los cálidos húmedos, así como con la existencia de tipos de suelos de una notable diversidad, muchos de ellos favorables para la actividad agrícola. La altitud también marca diferencias en los tipos de vegetación, modificando los paisajes según se vaya de las planicies a las pendientes moderadas y de las laderas más escarpadas a las cimas de las montañas. Los biólogos conocen esta variación como cambios ambientales altitudinales, propia de las montañas tropicales. La secuencia comienza con la vegetación costera, siguiéndole la selva tropical húmeda, la selva alta perennifolia, el bosque mesófilo y finalmente el bosque de niebla en las partes más altas, donde se encuentra un clima más bien templado.

Gracias a la selva, y frecuentemente también a pesar de ella, grupos humanos han podido establecerse y desarrollarse o lo largo de un gran periodo de tiempo. Desde los primeros pobladores de la Sierra establecidos ahí hace unos 3,400 años (Stanley 1996), hasta los actuales campesinos indígenas y mestizos, han aprovechado, y a veces arrancado, los múltiples recursos que les ha ofrecido la selva y, con ello, logrado, unos con más éxito que otros, reproducir sus modos de vida. Los suelos de esta región, ricos en minerales, han sustentado a muchas poblaciones con diferentes culturas a través de los siglos y han permitido dos cosechas anuales y al sur de la Sierra hasta cuatro (Coe 1981, 15-20). En la actualidad, sin embargo, la Sierra es, en su mayor parte, un inmenso potrero para la cría de ganado vacuno. Dada la tecnología, métodos y técnicas usadas en la producción en el pasado, la Sierra se mantuvo relativamente intacta. En las últimas décadas, sin embargo, ha sufrido un ataque casi mortal y la pérdida de especies y de la cubierta forestal ha tomado ritmos nunca antes vistos.

Con éxitos parciales y con fracasos, introduciendo conflictos o renovándolos, tratando de fomentar -a veces contradictoriamenteprácticas productivas más acordes con el entorno y promocionando 
la conservación, en la Sierra, desde los ochenta, se han implementado programas que han intentado apaciguar la implacable deforestación alimentada por décadas de aprovechamiento extensivo. En 1979 se decretó al volcán San Martín Tuxtla como Zona Protectora Forestal y de Refugio Faunístico con una superficie de 5,630 ha y en 1980 a la Sierra de Santa Marta y al volcán San Martín Pajapan como Zona de Protección Forestal y Refugio de Fauna Silvestre, reclasificada en 1988 como Reserva Especial de la Biosfera con 82,800 ha de extensión. ${ }^{2}$ En 1998, a través de un decreto presidencial, se estableció un proyecto más ambicioso, la Reserva de la Biosfera "Los Tuxtlas", con una extensión de 155,122 ha, e integrada por una zona de amortiguamiento que cubre a tres zonas núcleo, cada una situada en los lugares más elevados y mejor conservados de los volcanes San Martín Tuxtla, Santa Marta y San Martín Pajapan.

Hoy cuatro municipios veracruzanos convergen en la Sierra de Santa Marta: Soteapan, Mecayapan, Tatahuicapan y Pajapan, habitados principalmente por indígenas nahuas y popolucas, y cuyas cabeceras están asentadas en las faldas de los volcanes, a una altura de entre 200 y $400 \mathrm{msnm}$. A principios del siglo XxI, los hablantes de estos idiomas indígenas representan más de tres cuartas partes del total de la población en estos cuatro municipios (INEGI 2010). En conjunto, en los cuatro municipios de la Sierra existe una población de 60,653 habitantes de cinco años y más, de los cuales $76.2 \%$ habla alguna lengua indígena. El de mayor población es Soteapan con más de veinte mil habitantes; de los cuatro municipios también es el que tiene el porcentaje más alto de hablantes de lengua indígena con respecto al total de su población (83.5\%). La población de los otros tres municipios, Pajapan, Tatahuicapan y Mecayapan oscila entre los diez y trece mil habitantes y también tienen una fuerte presencia indígena que representa a más de $60 \%$ de sus poblaciones. En esta zona popolucas y nahuas de la Sierra conviven en un espacio inter-

${ }^{2}$ Desde la declaratoria de la Zona de Protección Forestal y Refugio de Fauna Silvestre en 1980 y hasta 1991 se perdieron más de 10 mil hectáreas de selvas y bosques, "de tal forma que la superficie con cobertura arbórea densa que quedaba dentro del área declarada como reserva alcanzaba apenas 33,296 ha, lo cual representa $40.3 \%$ del área protegida decretada en 1980" (Ramírez 1999, 202). 


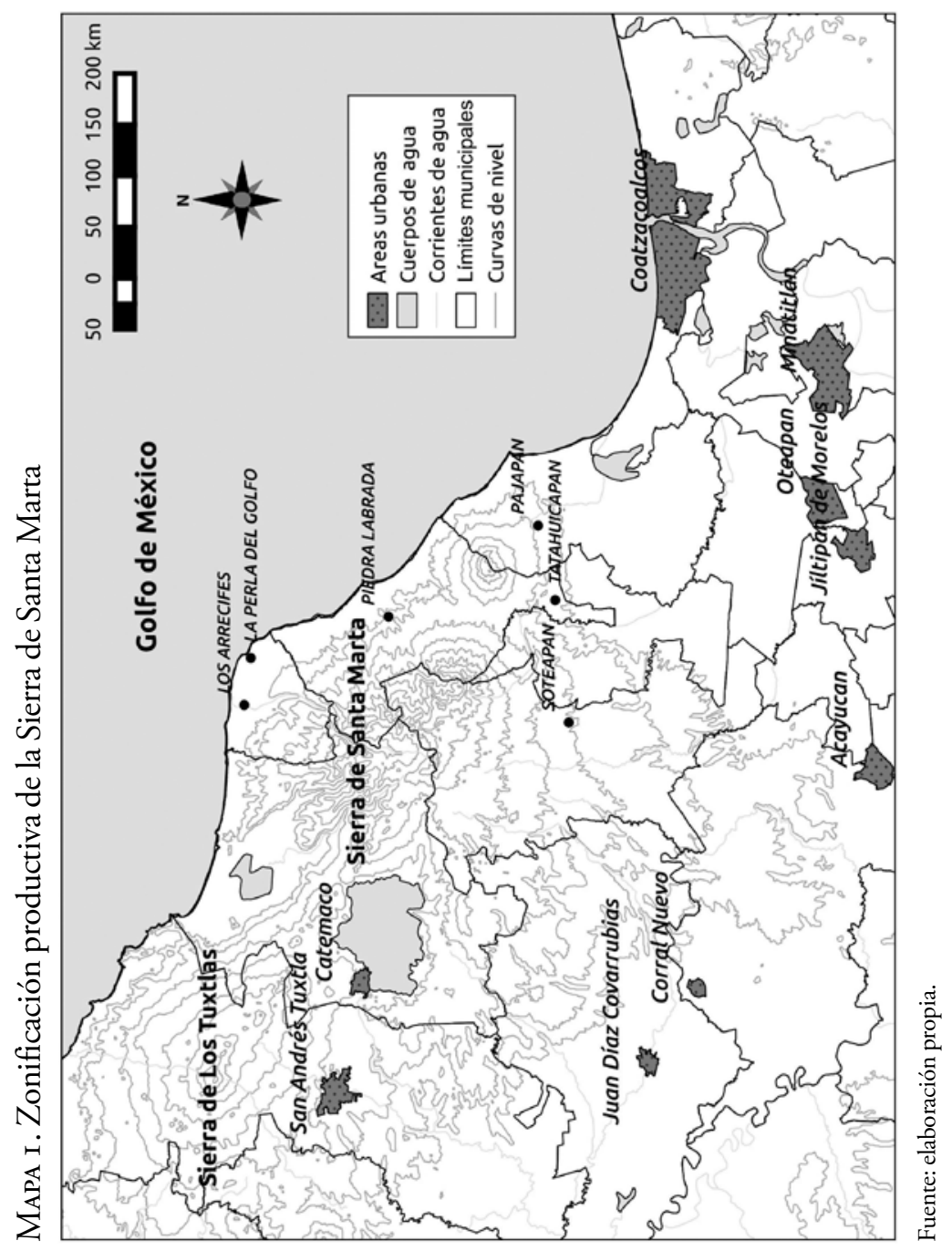


étnico al que se han integrado mestizos provenientes de otros municipios del estado así como de otros estados del país (véase Paré y otros 1993).

En este espacio natural y cultural se han desarrollado diversas estrategias productivas a lo largo del tiempo: la agricultura tradicional del maíz y sus cultivos asociados como tomate, frijol y calabaza; el cultivo de café y otros productos comerciales; la producción ganadera; la extracción forestal, entre otras. Actualmente se sigue recurriendo a aquellas formas productivas, sin embargo, la presencia de la ganadería como actividad económica predominante hoy es evidente, particularmente, al norte y al oriente de la Sierra. Una regionalización elaborada hace poco más de una década puede servirnos para mostrar lo anterior, y aunque puede ser que las magnitudes y ritmos de las actividades a las que hace referencia se hayan modificado, sigue caracterizando pertinentemente una tendencia general. Así pues, existen cuatro zonas productivas en la Sierra de Santa Marta (véase mapa 1): a) zona ganadera, al norte, occidente y noroccidente, así como una pequeña porción hacia el centro, donde más de $80 \%$ de esta superficie está ocupada por pastos y donde se ubica la comunidad de Piedra Labrada además de otras vecinas como Zapotitlán y Mirador Pilapa; b) zona cafetalera, ganadera y milpera, hacia el suroeste del volcán Santa Marta; c) zona milpera, hacia el extremo sur de la vertiente meridional del volcán Santa Marta; y d) zona ganadera-milpera.

\section{Expansión ganadera en la Sierra de Santa Marta: PERVERSIÓN DEL ACCESO COMUNAL A LA TIERRA}

El proceso de expansión de la actividad ganadera hacia la Sierra inició mucho antes de que los ejidatarios de Piedra Labrada y los demás pueblos del interior de la Sierra comenzaran a adoptarla mediante tratos productivos conocidos como "renta de pastos" y "ganado a medias"; al menos 40 años antes, y fue parte del proceso nacional de expansión del sector hacia los trópicos. Hasta los años cuarenta del siglo $\mathrm{xx}$, las regiones tropicales del país eran y se consideraban como grandes reservas territoriales, con todo un futuro 
productivo - particularmente agrícola- por delante, y las plantaciones de cacao, plátano, cańa de azúcar o tabaco, cuyo objetivo eran los mercados internacionales, fueron la estrategia económica predominante hasta los años treinta en las zonas tropicales (Villafuerte y otros 1997). ${ }^{3}$

Sin embargo, sería la frontera ganadera y no la agrícola la que finalmente se expandiría sobre el trópico húmedo transformando en sólo unos años miles de hectáreas de selvas en campos de pastoreo. El crecimiento y la expansión de la ganadería tienen un periodo de crecimiento explosivo entre los cuarenta y cincuenta, época en la que la superficie de pastos aumenta $42.4 \%$ en seis estados del trópico (Veracruz, Chiapas Quintana Roo y, sobre todo, en Tabasco, Campeche y Yucatán), pasando de 3.6 a 5.2 millones de hectáreas. Diez años más tarde, la superficie alcanzó poco más de 6.1 millones (96\% del crecimiento tuvo lugar en Veracruz, Chiapas y Yucatán) y, para 1970, la superficie ocupada por pastos naturales y cultivados llegaba a los 6.7 millones de hectáreas (Villafuerte y otros 1997).

En la Sierra de Santa Marta, a finales de los cuarenta, la mayor parte de la superficie estaba cubierta por una densa selva lluviosa, exuberante y -según relatos de sus habitantes- peligrosa e intimidante para quien se aventurara a sus entrańas. Para entonces la presencia de pastos era absolutamente minúscula, casi imperceptible. Así, para 1949, las superficies ocupadas con pastos en los municipios de Soteapan y Mecayapan eran respectivamente de 2.4 y $0.8 \%$ en relación con la superficie total (Paré y otros 1993). En Pajapan al sureste- era un poco distinto y para ese mismo ańo el porcentaje de la superficie ocupada por pastos era ya de $27.9 \%$. Hacia finales de esa década de 1940, el triunfo a escala nacional y regional del

${ }^{3}$ No es que la actividad ganadera no existiera bajo la humedad y el calor de los trópicos. En algunos lugares, como el sur de Veracruz, de hecho, la ganadería vacuna fue una actividad económica relevante durante la Colonia y la estancia ganadera fue desde los comienzos del establecimiento espańol parte inseparable de los paisajes bajos y cálidos veracruzanos (véase Delgado 2000 y Alcántara 2007), pero en comparación con la producción ganadera en los altiplanos áridos y semiáridos, en los trópicos su desarrollo fue lento y a diferencia de su desarrollo posterior, no originó daños considerables a la estructura de la vegetación ni en la composición de especies en los ecosistemas que ocupó (Guevara 2001, 2-3). 
proyecto alemanista sobre las ideas cardenistas de cuño agrarista permitió la consolidación en el sur de Veracruz de un grupo ganadero de enorme fuerza política y económica, irradiada desde los centros de poder regional como Acayucan y Coatzacoalcos y canalizada a través de la Unión Regional Ganadera y sus filiales locales (Velázquez 2000, 113-114). Así, en Pajapan, una comunidad agraria nahua que a diferencia de sus vecinos popolucas de Soteapan había podido evitar durante el Porfiriato la pérdida de sus tierras comunales (véase Velázquez 2006, 2001), la expansión de la ganadería comenzaba a expresarse en una lucha de poder entre diferentes actores en un ámbito circunscrito no meramente a lo local entre campesinos, elites económicas y políticas y organizaciones ganaderas (véase Buckles y Chevalier 1993). En este municipio, pronto hubo campesinos indígenas que se apropiaron rápidamente de la ganadería como una forma viable de ganarse la vida aun a costa de los recursos forestales que desaparecían a su paso. La presencia de la ganadería impregnó con su sello la política local y los conflictos de interés en las contiendas políticas municipales tuvieron en su centro la posibilidad de seguir extendiendo las superficies de pastos y un mayor número de reses.

Pequeńos ganaderos locales y ganaderos de Coatzacoalcos, en alianza, habían aprovechado el acceso comunal a la tierra para, mediante el arrendamiento, tratos de medianía y a veces la ocupación impune, hacerse de tierras, desplazando a los cultivos hacia lugares más altos y menos fértiles (véase Chevalier y Buckles 1995). Para hacer frente al acaparamiento de tierras por parte de los ganaderos, los campesinos de Pajapan, ya desde los treinta, líderes y autoridades municipales habían solicitado la dotación ejidal como medida para proteger sus tierras y cultivos que comenzaban a ser invadidos por ganado ajeno. La estrategia no tuvo éxito y los ganaderos de Coatzacoalcos respondieron con el asesinato de tres presidentes municipales. Cuando los esfuerzos se renovaron una década después y se formó otro comité agrario buscando la dotación ejidal, la oposición devino ya no sólo de los ganaderos de Coatzacoalcos, sino también de pequeños productores locales con el apoyo de aquéllos. Para 1951, las autoridades municipales, dominadas ya por ganaderos, 
nuevamente formaron otro comité agrario para solicitar ya no la dotación ejidal, sino el reconocimiento y la titulación de bienes comunales, este proceso culminó con la resolución presidencial en ese sentido en 1968 (Buckles y Chevalier 1993).

En el municipio vecino de Mecayapan, la historia no fue muy diferente y aunque un poco después que Pajapan, en los cincuenta, aquí también los líderes ganaderos de las asociaciones regionales y locales, a través del control que ejercían sobre los comités agrarios, fueron retrasando la dotación ejidal favoreciendo la concentración de tierras por parte de los ganaderos locales. Aun después de otorgada la dotación ejidal las tierras se mantuvieron en uso común y con ello siguieron los actos de acaparamiento mediante el cercado de superficies de 100 y más hectáreas (Velázquez 1992) y que se iban extendiendo sobre las zonas más planas y fértiles, razón por la cual se comenzó a demandar el parcelamiento de las tierras ejidales (Lazos 1996, 207). A diferencia de Pajapan y Mecayapan, en Tatahuicapan, entonces una comunidad del municipio de Mecayapan, la expansión de la ganadería se debió a los campesinos que mediante la conjunción de dinero y trabajo crearon cooperativas de encierro para posibilitar la producción pecuaria, sin recurrir a la intervención -al parecer, al menos en Tatahuicapan- de contratos de mediería, comunes en el municipio de Pajapan (Lazos 1996).

Los proyectos de colonización agraria, el reparto agrario y, más tarde, los programas de financiamiento gubernamental le dieron nuevos impulsos a la expansión y al desarrollo de la ganadería en la Sierra. Por un lado, el Plan Nacional de Colonización -cuyo propósito era establecer un régimen de propiedad rural con la finalidad de colonizar tierras y favorecer el poblamiento e incremento de la producción agrícola y ganadera- llevó, en los cincuenta y sesenta, a cientos de hombres y mujeres y sus familias, provenientes de las zonas ganaderas del centro del estado, a poblar áreas específicas de la región. Estas familias establecieron colonias como la Perla del Golfo, en el municipio de Mecayapan; La Magdalena, en el municipio de Soteapan; y Adalberto Tejeda, en el municipio de Catemaco (Velázquez 2006). Por otro, sobre todo a partir de los sesenta, inicia en el interior de la Sierra un proceso de dotación de tierras ejidales. 
Hasta los cincuenta, al oriente y nororiente de la Sierra, además de Piedra Labrada solamente existían las localidades nahuas de Los Arrecifes, Sochapan, y la comunidad popoluca de Mirador Pilapa. Con el reparto agrario, el espacio selvático de esta parte de la Sierra fue poblándose paulatinamente con nahuas del municipio de Mecayapan, popolucas de Soteapan, así como con gente de regiones vecinas -sobre todo de Los Tuxtlas- (Velázquez 2006), establecieron ejidos como La Valentina, Pilapillo, Santanón Rodríguez, Benigno Mendoza, Venustiano Carranza y otros, algunos estuvieron orientados desde su creación a la ganadería (Lazos 1996; Paré y otros 1993; Durand 2000; Castellanos 2010). Así, la mayoría de las localidades del interior de la Sierra ubicadas al norte y al oriente, fueron fundadas en los sesenta y setenta, aunque todavía en la siguiente década se formaron algunos poblados (Velázquez 2006, 353).

Fue en estas décadas cuando tuvo lugar una verdadera expansión de los potreros a costa de la cubierta vegetal. De hecho, entre 1972 y 1986, esta zona fue la que perdió la mayor extensión de bosque en el conjunto formado por las sierras de los Tuxtlas y Santa Marta. En este periodo, la actividad productiva que giró de la agricultura a la ganadería, provocó una intensa fragmentación de la selva que tuvo como consecuencia el aislamiento de la vegetación del macizo de Santa Marta de la del macizo de San Martín Pajapan (Guevara y otros 2004, 95). Hoy, sólo en las cimas de los volcanes, cubiertas frecuentemente por una espesa neblina, puede apreciarse una selva todavía viva. Otros remanentes pueden observarse en los bordes de ríos y arroyos. En el ondulante relieve de la región son visibles también algunos acahuales de diferentes edades, así como árboles aislados, remanentes de la cobertura original de la selva, tocones y troncos pudriéndose sobre la tersura de los pastizales y al lado de las cercas, galeras, corrales y pequeñas cabañas que conforman las instalaciones básicas de la actividad ganadera.

De la misma manera en que estas formas de ocupación y transformación del espacio ligadas a dos formas diferentes de tenencia de la tierra -la colonia y el ejido-impulsaron la ganaderización de la Sierra, el otorgamiento de créditos oficiales también tuvo un papel importante. En la primera mitad de los setenta, la Comisión Coor- 
dinadora para el Desarrollo Integral del Istmo de Tehuantepec y el Fideicomiso Ejidal Ganadero, llevaron los primeros programas de asesoría técnica y de crédito para la ganadería campesina. Ambos proyectos culminaron en la segunda mitad de la década, absorbidos por el Programa Integral para el Desarrollo Rural creado en 1973-y desaparecido en 1983-a sugerencia del Banco Mundial e interesado en promover la modernización y la monetarización de las economías rurales como estrategia para abatir la pobreza. Los créditos provenientes de dichos programas, que se concentraron principalmente en las cabeceras municipales (Soteapan, Mecayapan y Pajapan) y en algunos poblados cercanos, como fue el caso de Tatahuicapan, permitieron que campesinos sin recursos incursionaran en la actividad ganadera, dejando de ser ésta "coto privilegiado de una pequeña elite local, lo que a su vez dio fuerza a la lucha contra el acaparamiento de tierras" ejidales (Velázquez 2000, 117). Asimismo, la banca comercial y BANRURAL extendieron créditos a lugares donde los programas no habían llegado, generalmente a poblaciones del interior de la Sierra como Magallanes, San Francisco Agua Fría, Benigno Mendoza y Piedra Labrada.

La crisis económica de comienzos de los ochenta y las políticas de ajuste que le siguieron tuvieron grandes efectos sobre la actividad pecuaria, que entró también en una crisis estructural de considerables proporciones (véase Villafuerte y otros 1997; Rutsch 1984). La producción decayó y los créditos e instituciones de apoyo al sector fueron paulatinamente restringidos o eliminados. En este contexto de crisis nacional, el crecimiento de la ganadería en la Sierra de Santa Marta perdió intensidad, aunque siguieron abriéndose nuevos potreros y la actividad ganadera se expandió a través de la mediería en ganado, del "alquiler de pastos" y de la venta de derechos agrarios, sobre todo, en aquellos lugares que quedaron marginados de los créditos bancarios (Paré y otros 1993). Fue precisamente a través de los contratos de mediería y de "alquiler de pastos" que ganado y pastos comenzaron a invadir el espacio anteriormente destinado a los cultivos de maíz y el ocupado por la cobertura vegetal selvática y Piedra Labrada comienza a ser absorbida en la actividad ganadera. Hoy la ganadería es la principal actividad económica tanto en la 
comunidad como en otras vecinas y el "ganado a medias" sigue siendo la manera más común en la que un campesino puede obtener ganado o ampliar su hato.

\section{Piedra Labrada: de agricultores a ganaderos}

Piedra Labrada se fundó en 1908 a un costado de un antiguo asentamiento olmeca del que lo separa el río Sochapan. Éste corre paralelamente al poblado en su lado oeste y a diario es cruzado, a través de dos frágiles puentes colgantes, por los ejidatarios en su camino hacia sus parcelas. Los primeros pobladores llegaron al lugar escapando de la violencia generada por el levantamiento armado dirigido por líderes magonistas radicados en las ciudades de Coatzacoalcos, Minatitlán y Acayucan, y en la que los zoque-popolucas del municipio de Soteapan jugaron un papel protagónico (Báez-Jorge 1990; Velázquez 2006). Según lo relata don Fidencio Gutiérrez, de 94 años e hijo de uno de los fundadores del pueblo, después de permanecer algunos días en su campamento ubicado en las espesuras de la selva, los refugiados, considerados rebeldes armados, fueron encontrados por un pequeño destacamento de federales, quienes, sin embargo, no lograron encontrar arma alguna ni líderes del movimiento "más que puros campesinos, criando maíz y cochinos". El jefe de la persecución, al creer que los líderes habían escapado más al norte, decidió entonces ir tras ellos, pero al cruzar el río Sochapan fue arrastrado por la fuerte corriente; sus soldados, al no poder hacer nada por él, regresaron por donde habían llegado no sin antes destruir las propiedades de los campesinos ahí establecidos. Después de un tiempo de estar en la montaña, varias familias regresaron a sus poblados de origen: Hueyapan de Ocampo, Ocotal Chico y Soteapan, pero otros decidieron establecerse en el lugar definitivamente. No fueron muchos los que así lo hicieron, pues, en 1925 cuando Blom y La Farge visitaron el sitio prehispánico encontraron que cerca de ahí habitaba una sola familia extensa popoluca.

Durante toda la primera mitad del siglo xx, el interior de la Sierra fue un lugar prácticamente deshabitado; además de Piedra Labrada, solamente existían las comunidades nahuas de Los Arrecifes y de 
Sochapan, más al norte. Piedra Labrada y Mirador Pilapa -esta última fundada en los años treinta-, aisladas por un mar de selva, lejos de la cabecera municipal y sus poblaciones distantes de su parentelas, disminuyeron rápidamente su interacción con los centros popolucas del occidente de la Sierra, que después de su experiencia colectiva en los movimientos armados en los años precedentes se encerraron sobre sus comunidades y asumieron una actitud conservadora, reticente al contacto con extraños (Bradley 1988, 144). ${ }^{4}$ Este aislamiento, desde luego era relativo. Personas que habitaban en el interior de la selva mantenían contactos regulares con las comunidades fuera de ella. Caminando a través de la playa, algunos hombres realizaban incursiones comerciales a Coatzacoalcos, durante los treinta, llevando huevo y gallinas para ser vendidos en aquel puerto y para realizar a su vez algunas compras. En Piedra Labrada también hay quien afirma haber trabajado como albañil durante la incipiente actividad económica en torno a la infraestructura petrolera en Minatitlán en los mismos años.

Por la playa también llegó el primer ganado del que se tiene noticia, desde Pajapan. Mientras en este municipio los comuneros locales se enfrentaban a los ganaderos de Coatzacoalcos en una lucha por mantener el acceso a sus tierras comunales y los recursos que había en éstas, en el interior de la Sierra el ganado era poco, pero no extraño. De acuerdo con lo dicho por un ejidatario popoluca de Piedra Labrada, en esa década, su abuelo, en un pequeño asentamiento llamado el Zacatal ubicado en la costa y en el mismo lugar donde se instalarían ańos después los colonos mestizos de La Perla del Golfo, poseía "más de veinte cabezas de ganado". Pocos años más tarde, algunas personas de Piedra Labrada, según se desprende del censo realizado en 1957 en vista de la dotación ejidal, ya poseían también unas cuantas cabezas de ganado (en total había 105 cabezas). ${ }^{5}$

${ }^{4} \mathrm{~A}$ partir de los cincuenta y, sobre todo, en los sesenta, inicia en este lugar el proceso de dotación de tierras ejidales, el espacio selvático de esta parte de la Sierra fue poblándose paulatinamente con nahuas del municipio de Mecayapan, popolucas de Soteapan, así como con gente proveniente de otros lugares del estado (véase Velázquez 2006).

${ }^{5}$ Archivo de la Comisión Agraria Mixta (АСАM), expediente de dotación ejidal de Piedra Labrada, consultado en el Archivo General del Estado de Veracruz (AGEV). 
Así, desde los cincuenta en la zona había ganado mayor y de hecho, la incipiente ganadería comenzaba a generar en Piedra Labrada problemas similares a los ocurridos en Pajapan y Mecayapan. Los aspirantes a ganaderos habían comenzado igualmente a cercar parte de las tierras que hasta entonces eran de uso común, lo cual generaba conflictos con el resto de los ejidatarios. La presencia de ganado fue, de esta manera, una de las razones por las que los campesinos zoques-popolucas decidieron parcelar el ejido. Incluso eso fue motivo para que una persona quedara fuera del reparto, ya que el perito agrario encargado de realizar el estudio para la dotación de ejido argumentó que no cumplía con las requisitos socioeconómicos para ser beneficiado. Debido a los incipientes problemas generados por la posesión de ganado por parte de algunos pobladores, poco después de la posesión definitiva, en 1963, se terminó en Piedra Labrada con el acceso comunal a la tierra y las tierras recibidas se dividieron en 40 parcelas de 20 ha, una parcela a cada uno de los 39 "capacitados" y una parcela escolar. ${ }^{6}$

Para 1960, Piedra Labrada contaba con 257 habitantes, más del doble que en la década anterior (121 en 1950). A pesar de la presencia de ganado, durante esa década y la siguiente, Piedra Labrada siguió siendo un pueblo de agricultores milperos de autoconsumo, cuyos cultivos principales eran el maíz, frijol y arroz; también se dedicaban a la crianza de cerdos, de los cuales obtenían carne y manteca. La caza de aves y mamíferos silvestres así como la abundante pesca de peces y de camarón tanto en el mar como en los ríos de la zona complementaban la dieta básica. El poco ganado que lo-

${ }^{6}$ La resolución presidencial que dotó con tierras ejidales a Piedra Labrada tuvo lugar en 1961, y apareció en el Diario Oficial de la Federación el 31 de enero del año siguiente, aunque la posesión definitiva no se llevó a cabo sino hasta 1963. La resolución les otorgó una extensión de 970 ha, distribuidas en 800 de temporal, 156 de agostadero y monte y 14 ha para la zona de urbanización, tierras tomadas de la finca denominada "segunda zona de Romero Rubio”, que para entonces era propiedad de Petróleos Mexicanos. La resolución presidencial se realizó veinte años después de la solicitud de dotación, hecha en 1942, año en el que fue iniciado el expediente. Puesto que los recién llegados colonos de La Perla comenzaron a ocupar grandes extensiones de tierra sobre la costa, desde el norte hasta los pies del volcán San Martín, el proceso que legalizó la posesión provisional se aceleró, ejecutándose en 1959. 
graba ser reunido para su venta en pie, era trasladado por arrieros hasta Sontecomapan, bordeando la costa hacia el noroeste. De acuerdo con los ejidatarios de mayor edad, hubo incluso un momento en el que había suficiente maíz como para satisfacer a los principales compradores de otros lugares como San Juan Volador y Pajapan, quienes acudían a Piedra Labrada para obtenerlo.

En la memoria de los ejidatarios de mayor edad, esta situación permanece como un recuerdo de la abundancia y la plena autosuficiencia en contraste con la actual economía local caracterizada por el uso del dinero y la dependencia, y en el que se contrapone lo natural a lo artificial:

Antes la verdad no se compraba aceite, lo que ahorita se consume, porque toda la gente mataba un cochino y tenía manteca para lo necesario; entonces la gente no compraba frijol, ni arroz, ni maíz; todos sembraban: plátano, piña, cańa; toda la gente cosechaba y no había nada de que voy a comprar arroz o frijol. Pero caminando el tiempo cuando toda esta gente fue creciendo pues como que también todo desapareció; y ya cuando viene la ganadería entonces la gente empezó con la ganadería, empezaron a tumbar y a empastar. Aquí la comida era la mas rica; A nosotros nos criaron a base de pura comida natural, el pescado, el camarón, el burrito, el faisán, venado, tuza, todo lo que la tierra da, lo natural y hoy en día cambia, hay enfermedades; en aquellos tiempos no había enfermedades, no había doctor como ahorita, nada (Atilano Albino, ejidatario, 73 años).

El paso de agricultores a ganaderos en Piedra Labrada tuvo lugar en un periodo relativamente corto y comenzó a darse, paradójicamente, en un contexto de crisis nacional para el sector ganadero. Como se ha dicho, la crisis económica a comienzos de los ochenta tuvo grandes efectos sobre la actividad pecuaria, que entró también en una crisis estructural de considerables proporciones (véanse Villafuerte y otros 1997; Rutsch 1984). La producción decayó y los créditos e instituciones de apoyo al sector fueron paulatinamente restringidos o eliminados. En la Sierra de Santa Marta, el crecimiento de la ganadería también disminuyó aunque, sobre todo, en aquellos lugares que quedaron al margen de los créditos bancarios, siguió 
su expansión a través de la mediería, el alquiler de pastos y la venta de derechos agrarios

La apertura en 1982 de un camino de terraceria accesible desde Tatahuicapan, distante de Piedra Labrada $24 \mathrm{~km}$ de sinuosa terracería, posibilitó este proceso. Las relaciones económicas de Piedra Labrada con otras poblaciones se hicieron más frecuentes, comerciando productos en Tatahuicapan y posibilitando que gente de esta localidad se trasladara en La Perla del Golfo para contratarse como jornaleros para el desmonte y deshierbe en los campos de chile o en los potreros. En Piedra Labrada también se adoptaron nuevos cultivos, como el chile serrano que los productores vendían en la Perla del Golfo.

En el contexto de esta apertura, la expansión ganadera alcanzó a Piedra Labrada por dos caminos: mientras algunos ejidatarios ofrecían pastos a ganaderos de diferentes lugares, sobre todo, a los rancheros mestizos de San Francisco Agua Fría o La Perla del Golfo, otros, un poco antes, comenzaron a establecer convenios de ganado "a medias" con mestizos establecidos en otros lugares del estado. Con los años, la agricultura quedaría subordinada casi por completo al desarrollo de la ganadería.

El primero de estos tratos productivos que posibilitaron la actividad ganadera en Piedra Labrada es conocido como "renta de pastos". Algunos autores lo han denominado "renta de piso" (véase Robles 2005). El término local refleja más adecuadamente lo que los productores quieren decir con él. Los ejidatarios ponen su atención en otro lugar, en el pasto y no en el piso. Es por eso que algunos conocen al trato no como una "renta de piso", sino como una "renta de pasto". No es exactamente el piso lo que están cediendo sino el pasto, estrictamente la hierba inducida que crece sobre su propiedad. Los dueños del ganado no tienen derecho alguno sobre la propiedad y los recursos que allí existen, sino únicamente sobre el pasto por el que han pagado y que sirve de alimento para sus reses. De hecho, algunos otros ni siquiera consideran exactamente al mismo trato una renta, sino una "venta de pasto", lo cual tiene que ver con que los tratos no obligan a la persona que adquiere el pasto a mantener el convenio por un tiempo definido. Mediante este trato, los 
ganaderos mestizos de otros lugares encontraron en Piedra Labrada -y en otras comunidades de la Sierra- el pasto suficiente para su ganado; y los ejidatarios encontraron en él también una manera de ganar dinero para complementar sus ingresos. A finales de los ochenta y principios de los noventa la renta de pastos se volvió menos frecuente -aunque algunos siguieron dedicándose a ello hasta hace apenas unos ańos- ya que se le dio prioridad al manejo del ganado a medias y la creación de un hato propio.

Asimismo, igualmente en la primera mitad de los ochenta, se establecieron los primeros convenios de "ganado a medias" entre ejidatarios locales y ganaderos de otros lugares. De las tres personas que iniciaron con la actividad, uno, el primero, obtuvo en 1984 ganado de una persona del centro de Veracruz; poco después, los otros dos lo hicieron de un maestro de primaria originario de Chinameca. ${ }^{7}$ Este tipo de trato, hoy inexistente en el lugar, consistía en la cría de toretes de engorda con la participación igualmente de un ganadero privado y un ejidatario. El ganadero invertía cierta cantidad de dinero, llamada "casco", para la compra de un número determinado de toretes. El mediero se ocupaba de la engorda del ganado en su propia parcela. Cuando finalmente los animales alcanzaban el peso suficiente eran vendidos y el dinero obtenido se dividía en tres partes. La primera representaba la inversión inicial del ganadero, "el casco"; las restantes dos partes, divididas por igual, constituían la ganancia y una era para el ganadero y la otra para el ejidatario. Esta modalidad, introducida en los ańos iniciales de la ganadería, no fue muy extendida en la comunidad; los que lo intentaron, dos o tres personas, no tuvieron mucho éxito, pues, relatan que justamente durante esos ańos los precios bajaron y prácticamente no obtuvieron ganancias.

Casi paralelamente y de manera más importante, los pobladores de Piedra Labrada asumieron con productores de esas mismas ciu-

${ }^{7}$ El proceso común de cambio socioeconómico en las comunidades de la microrregión ganadero-milpera, iniciado a partir de 1980 y apoyado en el establecimiento de convenios de aparcería en ganado y de arrendamiento de pastos ha sido ampliamente descrito para la comunidad de Pilapillo ubicada en esta misma microrregión (véase Castellanos 2001). 
dades así como de otros lugares - "del centro del estado"- otra modalidad de mediería, que hasta hoy predomina en la economía local y regional y que fue la que posibilitó la adopción de la actividad. Este trato productivo es un convenio que se entabla oralmente, sin documentos escritos y sin un compromiso temporal definido. El trato se establece entre un ganadero, generalmente privado no originario de la región y un ejidatario que posee la cantidad de tierra suficiente para la pastura de ganado. El primero aporta capital circulante en la forma de pie de cría, mientras que el segundo lo hace con tierra, trabajo e insumos, como semilla para pasto, fertilizantes, vitaminas y medicamentos que casi siempre son aportados por él en su totalidad, aunque se pueda llegar a algún acuerdo con el dueño. Para el ejidatario, el beneficio que obtiene del convenio se concreta en especie: para él son la mitad de las crías y la leche de las vacas que han parido. La otra mitad de las crías son entregadas al ganadero privado a los siete u ocho meses de edad, después de que son destetadas. La repartición del beneficio se hace con estricto apego a la lógica de la división de $50 \%$ para cada una de las partes, tanto en número, como en el sexo de las crías. Si son cinco becerros los que habrán de repartirse, dos hembras y tres machos, por ejemplo, cada quien recibe dos, una hembra y un macho, y el quinto puede venderse y se reparten entre ambos el dinero o, bien, uno de ellos puede quedarse con un animal y pagar al otro el valor que corresponde. Hoy, practicamente, todos los ejidatarios mantienen tratos a medias con productores de otros lugares y la ganadería de doble propósito, que se lleva a cabo con ganado resultante de cruzas de razas cebuinas con ganado especializado como Suizo Pardo (véase Arriaga y otros 2000), es la actividad económica principal en Piedra Labrada. Los ingresos obtenidos de esta actividad derivan principalmente de la venta de leche a queseros de las localidades de Sochapan y San Francisco Agua Fría y de la venta de ganado en pie a intermediarios provenientes de otros lugares del estado como Tierra Blanca, Actopan y Jesús Carranza y del país, que periodicamente recorren la región.

En la segunda mitad de la década de 1980, las parcelas en Piedra Labrada tuvieron un uso intensivo en las que los campesinos com- 
Figura I. Distribución de áreas productivas en una parcela del ejido Piedra Labrada

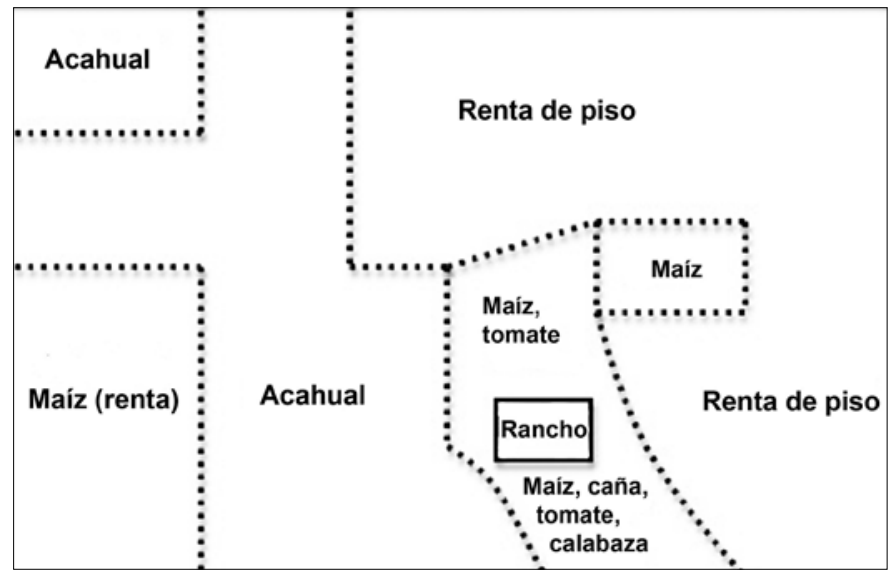

Fuente: Trabajo de campo (2009).

binaban diversas actividades agropecuarias que implicaban diferentes usos del suelo: un área para el cultivo del maíz, frijol y otros productos, otras para pastoreo y otra de acahual. El manejo y aprovechamiento de la parcela estaba basado en la rotación periódica de las diferentes secciones que componían la parcela, intercambiando las actividades realizadas en cada una de ellas. Es muy probable que las parcelas en aquel tiempo tuvieran una apariencia similar a la que se muestra en la figura 1, parcela aprovechada actualmente de manera similar por un ejidatario que no ha querido convertirse en ganadero y que además no tiene una opinión muy favorable sobre ellos (véase figura 1).

Esta sería una caracterización general de la producción campesina en Piedra Labrada durante los ochenta. El cambio más radical en torno a la actividad ganadera comenzaría a finales de esta década y a principios de los noventa, en particular, desde 1993, cuando las superficies de pasto crecieron con mayor velocidad -a expensas de los acahuales y de las zonas de cultivo- al tener los ejidatarios acceso a 
los recursos proveídos por el Programa Nacional para el Campo (PROCAMPO). Cada superficie desmontada para convertirla a potrero era primero sembrada con maíz para obtener los recursos del programa, y después de cosechada, se sembraba con pasto. En este sistema maíz-pasto, el cultivo de maíz ha quedado subordinado a la ampliación de las superficies de pastoreo, que se convirtió en un cultivo itinerante, aunque en un sentido distinto al tradicional. Es itinerante porque el maíz es cultivado cada vez en diferentes lugares de la parcela, aunque siempre siguiendo el ritmo de la expansión de los pastos. Éste fue el camino que varios ejidatarios siguieron para empastar sus parcelas; procediendo poco a poco, primero maíz y después pasto, fracción por fracción, un año tras otro. Cuando las superficies que empastar eran muy grandes, 4 o 5 ha, no se cubría enteramente de maíz o bien se le daba oportunidad a alguien más, un familiar o un amigo, de que realizara ahí su propio cultivo.

Actualmente algunos pocos siguen con este proceso, que piensan terminar hasta cubrir la mayor área posible de su parcela. La realización de una milpa depende casi enteramente de si existe la necesidad por parte de un ejidatario de renovar o cambiar el tipo de pasto que dispone. Si no hay tal necesidad, es probable que no sacrifiquen una hectárea de pasto por maíz. Los avecindados y campesinos sin tierra dependen en gran medida de este sistema de maíz-pasto. Cuando alguna persona, un avecindado o un ejidatario que ya ha empastado su parcela, dice que ha "rentado" tierras para hacer su milpa, generalmente quiere decir que consiguieron una porción de terreno que acondicionarán como campo de pastoreo a cambio del permiso que obtienen para sembrar su maíz.

En un proceso circular, la intensa degradación ambiental que ha sufrido esta microrregión de la Sierra, que ha terminado por ser convertida en su mayor parte en un inmenso potrero para la cría de ganado vacuno, ha sido igualmente un factor importante en el desplazamiento de la actividad agrícola por la ganadería. Los campesinos lo tienen en claro y cuando uno pregunta por qué ya no se cultiva maíz en extensiones mayores, generalmente se responde que ha sido debido a que las tierras han perdido fertilidad y, por lo tanto, hay que gastar en insumos que suplan o complementen las deficien- 
Foто ı. Ejido de Piedra Labrada

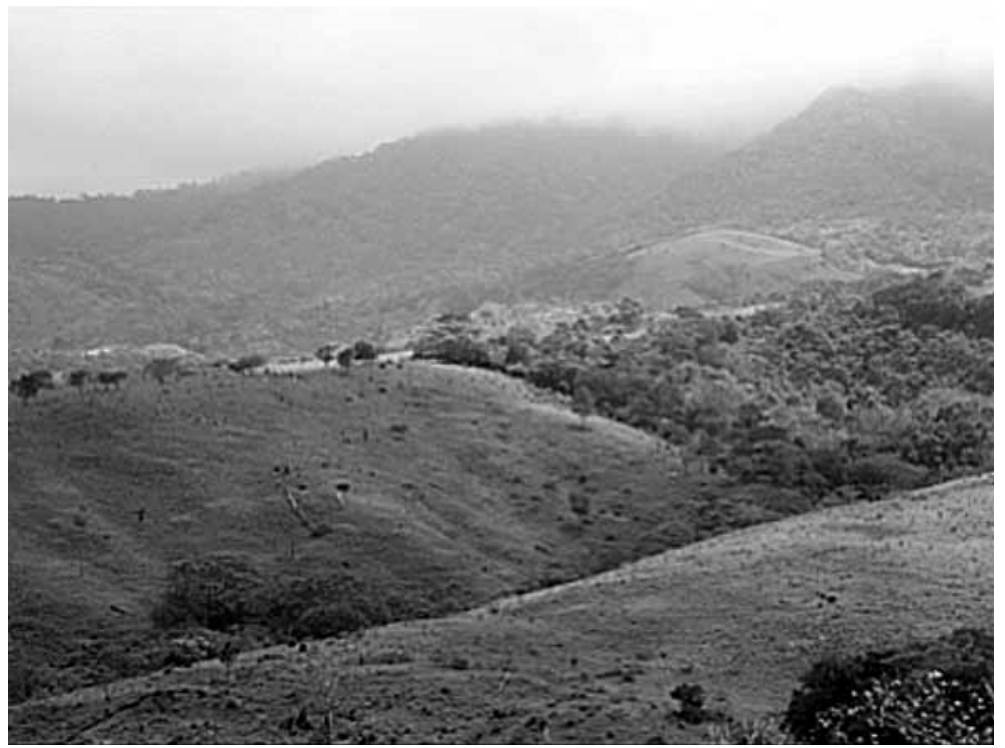

Fuente: fotografía del autor.

cias físicas y químicas del suelo. De las dos siembras de maíz que pueden realizarse, la menos común es la de invierno, ${ }^{8}$ ya que es necesario invertir más trabajo debido a las plagas y animales que hay en esta estación, además de que los vientos que cruzan del océano Pacífico al Golfo de México en los primeros meses del año, las "suradas", vuelven inviable el cultivo; como dijo un ejidatario: "es más fácil comprar maíz".

${ }^{8}$ En esta región es posible obtener dos cosechas al año; el cultivo de temporal se realiza en junio y se cosecha en septiembre, mientras que el cultivo de invierno o tapachole se hace en diciembre y la cosecha es en marzo o abril. Los meses indicados son los más comunes aunque debido a la alta humedad y precipitación pluvial los periodos de cultivo pueden variar y hay quienes siembran el temporal en mayo y el tapachole en noviembre o incluso en enero.

${ }^{9}$ En el ciclo de invierno 2006-2007, solamente 14 personas entre ejidatarios y avecindados cultivaron maíz, cubriendo una superficie de sólo 18 ha, con un promedio de 1.3 ha por persona. 
Foто 2. Ejido de Piedra Labrada

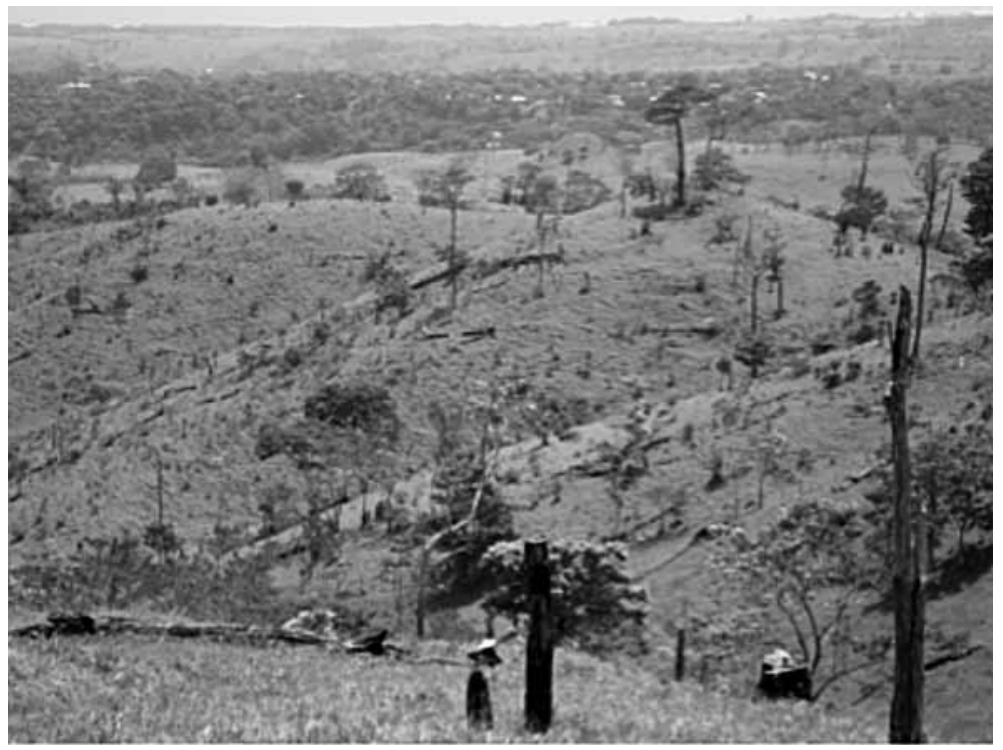

Fuente: fotografía del autor.

\section{El PROCEDE: CAMBIOS SOCIOCULTURALES Y PÉRDIDA} DEL CONTROL SOBRE LA TIERRA

Ya con una economía básicamente ganadera y con gran parte de la selva desaparecida, la comunidad de Piedra Labrada todavía tuvo que experimentar otros cambios importantes que han tenido profundas implicaciones para la organización sociocultural de la comunidad, principalmente, para la organización familiar y las reglas de la herencia de la tierra. Entre los ańos de 1994 y 2002, cuando se implementó el Programa de Certificación de Derechos Ejidales y Titulación de Solares Urbanos (PROCEDE), la mitad de la superficie ejidal fue trasferida a través de tratos de compraventa a manos externas, principalmente a rancheros de otras localidades vecinas como San Francisco Agua Fría, El Laurel y La Perla del Golfo.

El rasgo más importante de este mercado de tierras fue que los vendedores fueron principalmente aquellos que recibieron, poco 
antes o durante la implementación del PROCEDE, como herencia, las parcelas de sus padres o abuelos. Siguiendo la prescripción cultural que indica heredar la tierra al hijo hombre de menor edad, al ultimogénito, los ejidatarios dejaron en manos de éstos las parcelas que habían venido usufructuando desde que se creó el ejido, en los sesenta. Los hijos, al venderlas, rompieron así la continuidad en la posesión familiar de las parcelas ejidales. Aquellos que aún conservan sus parcelas piensan que es necesario acabar con esa regla cultural de la herencia para evitar nuevas ventas. Por ello es que las esposas ahora son las personas que se considera sí salvaguardarán el patrimonio familiar. Los tres ejidatarios que han fallecido en los últimos dos ańos dejaron en manos de sus esposas las parcelas aun cuando había hijos hombres y mujeres. Su papel anterior limitaba a estas mujeres a ser posesionarias transitorias -mientras uno de los hijos crecía- de los derechos ejidales de sus esposos. Ahora es probable que se conviertan en un factor esencial para la continuidad en la posesión de la parcela y del trabajo familiar y, por ende, de las demás formas de organización colectiva.

También hubo consecuencias ambientales. Si bien, la pérdida del bosque era ya casi completa, poco antes del PROCEDE todavía subsistía una pequeña reserva forestal, llamada "agostadero", que era utilizada para la extracción de leña y algunos otros recursos. Además, las parcelas mantenían pequeñas superficies en descanso o acahuales, utilizadas también como pequeñas reservas de extracción de leña. Por un lado, con el PROCEDE, el agostadero fue fraccionado en múltiples y minúsculas parcelas, las cuales fueron otorgadas a manera de compensación a los familiares de quienes habían vendido sus parcelas así como a algunos avecindados sin acceso a la tierra. Con esto, las pequeñas parcelas fueron trasformadas en campos de cultivo de maíz y otros productos e incluso pastos. Por otro, los acahuales en las parcelas que fueron vendidas desaparecieron, ya que éstas fueron obtenidas por rancheros dedicados a una ganadería extensiva, quienes sin tener la necesidad de extraer leña o cultivar maíz, empastaron la totalidad de la superficie (Flores 2007). Como resultado de este mercado de tierras, los hijos o hijas que anteriormente tenían acceso a la parcela de los padres para criar su propio ganado o 
cultivar maíz, de pronto vieron cancelada tal posibilidad y han tenido que migrar con mayor frecuencia hacia Oaxaca, donde asisten al corte de limón; a los campos de tomate de Sinaloa; y a las fábricas y maquilas de Ciudad Juárez, Chihuahua, y de Ciudad Acuña, Coahuila (véanse Flores 2007; 2011).

\section{COMENTARIOS FINALES: GANADERIZACIÓN, La Piedra labrada y su misterio}

El proceso de ganaderización a través de los tratos productivos descritos de la comunidad de Piedra Labrada significó, ante una producción agrícola casi de subsistencia y a pesar de la progresiva pérdida del bosque, una alternativa económica viable para sus habitantes, campesinos zoques-popolucas. Las condiciones para que eso -la expansión de la actividad pecuaria y la transformación del paisaje- fuera posible están vinculadas directamente con el papel asumido por el Estado a través de sus instituciones de gobierno y sus políticas públicas a través del tiempo. El impulso a la actividad ganadera como forma de expansión hacia las zonas tropicales del país, las políticas de colonización y de reparto agrario, sucesivamente, contribuyeron a configurar las formas de asentamiento y de actividad económica contemporáneas de la región. Estos grandes procesos nacionales afectaron la capacidad de producir alimentos básicos, de forma directa la capacidad de producir el maíz que se consumía. Pero no sólo eso. Las políticas públicas también contribuyeron a la pérdida del control de los recursos ejidales, como la tierra. Después de la implementación del PROCEDE, se desarrolló localmente un mercado de tierras en el que se transfirió la mitad de la superficie ejidal a manos de ganaderos privados de otras regiones del estado. Varios procesos socioculturales, económicos y ambientales se han desdoblado desde entonces: la transformación de las reglas de la herencia; mayor restricción en el acceso a la tierra para aquellos que no tienen donde cultivar; la migración como recurso; y la transformación de las tierras en descanso y del antiguo "agostadero" en campos de pastoreo, etcétera.

La configuración de una cotidianidad económica estructurada a partir de la actividad ganadera, desde luego, no fue un proceso 
mecánico, vertical, de arriba hacia abajo, sino que encontró condiciones que también la hicieron posible. Según la versión local, la ganadería fue un alivio a su condición de agricultores pobres. Un viejo, recordando como empezó la ganadería afirmó que: "Si no es por aquel rico [que les ofreció los primeros contratos a medias], nosotros vivimos más pobres que de todo. De ahí estamos comiendo, manteniendo nuestra vida material". Como lo sugiere la cita, es una idea común aquella que sostiene que quien tiene ganado es rico, en contraposición al milpero que es pobre, por lo que el prestigio de la actividad ganadera contribuyó y sigue contribuyendo a su adopción a través de contratos de medieria. La impresión se sustenta en el hecho de que es una actividad comercial que permite el flujo constante de dinero y la inserción cotidiana de los productores en un mercado de consumo, aunque las prácticas sigan siendo campesinas: el sostenimiento de la familia como objetivo principal de la actividad económica; el empleo de fuerza de trabajo familiar; la búsqueda de un ahorro en la forma de ganado para costear imprevistos y fiestas de quinceaños o bodas, por ejemplo, etcétera. En este proceso de ganaderización, la cuestión ambiental como un problema moral -es bueno y deseable cuidar de un recurso colectivo- y técnico, se supeditó al problema de la subsistencia o de la falta de recursos.

Además de la anterior explicación basada en la noción de pobreza y de aquella medioambiental -la reducción de la fertilidad de los suelos- que ofrecen los ejidatarios para responder a la pregunta de por qué ya no se cultiva maíz como antes y se vio en la ganadería una mejor alternativa para ganarse la vida, existe otra que a su vez hace comprensibles las anteriores. Para algunos fue la sustracción de la piedra labrada que sus abuelos encontraron en el lugar cuando llegaron por primera vez lo que provocó la trasformación productiva y, por tanto, los cambios en el paisaje, pues, ella tenía el poder de regular la existencia de maíz en las milpas. En los setenta, según la versión de los propios habitantes de la comunidad, un grupo de arqueólogos la removió de su sitio para trasladarla a una fría sala del Museo de Antropología de la ciudad de Jalapa, donde muchas personas la pueden ver, pero pocas saben del lugar que ocupaba en el orden simbólico de un pueblo. Para los pobladores de Piedra Labra- 
da fue su remoción lo que provocó que los suelos se erosionaran y ya no dieran maíz puesto que la piedra tenía "su misterio".

Por supuesto, la respuesta no es unánime entre la gente de Piedra Labrada. La población dejó de ser católica hace más de cincuenta años, convirtiéndose al protestantismo. Para otros, las explicaciones mágicas y supersticiosas de sus abuelos sobre el mundo social y natural son una cosa superada y ya sólo constituyen supervivencias para antropólogos curiosos del pasado, pero que no son recuperables, ni es deseable que lo sean. Sin embargo, el cambio de un sistema de creencias por otro, como se sabe, no es nunca total y siempre quedan secuelas que moldean las nuevas concepciones. Así, no es que algunos no crean que la Piedra Labrada haya sido "un dueño de las cosas", cuya presencia o ausencia haya determinado la abundancia o la escasez de maíz. De hecho lo hacen, pero ahora la creencia se fundamenta en diferentes preceptos: dejó de ser obra de "Dios" para pasar a ser obra del "Diablo"; si la ausencia de la Piedra Labrada fue lo que provocó la debacle productiva del maíz y, en última instancia, lo que determinó la adopción de la ganadería y, por ende, la desaparición de la cubierta vegetal, sólo puede explicarse porque había algo maligno en ella, porque "el Demonio a veces hace cosas admirables", aunque "ahorita ya no... ya no hay nada de eso".

\section{Bibliografía}

AlCÁNTARa López, Álvaro. "Élites ganaderas, redes sociales y desobediencia cotidiana en el sur de Veracruz del s. xvin". Historia Mexicana, vol. LVI, núm. 3 (2007): 779-816.

Arriaga, Carlos y otros. "Perspectivas y retos de la producción de leche en pequeña escala en el centro de México”. En Los pequeños productores rurales en México: las reformas y las opciones, comp. Antonio Yúnez-Naude, 219-260. México: El Colegio de México, 2000.

BÁEz-Jorge, Félix. Los zoque-popolucas. México: Instituto Nacional Indigenista, 1990.

Barrera-Bassols, Narciso. "Historia ambiental de la ganadería en Veracruz: 1519-1990”. Tesis de Maestría, México: Ciesas, 1995. 
Buckles, Daniel y Jacques Chevalier. "El ejido versus bienes comunales: historia política de Pajapan, Veracruz". En Desarrollo y medio ambiente en Veracruz: impactos económicos, ecológicos de la ganadería en Veracruz, coords. Narciso Barrera e Hipólito Rodríguez, 117-127. México: Fundación Frierich Ebert, Ciesas, Instituto de Ecología, 1993.

Bradley, Richard. Processes of Sociocultural Change in Southern Veracruz, Mexico. Tesis de Doctorado, The University of Oklahoma, 1998.

Castellanos, Alex. "Ganadería, medio ambiente y desarrollo sustentable. El proceso de adopción y/o aprobación de las propuestas sobre desarrollo sustentable y su relación con los impactos de la ganadería bovina extensiva en el sur de Veracruz". Tesis de Licenciatura en Antropología Social, México: Escuela Nacional de Antropología e Historia, 2001.

Chevalier, Jacques y Daniel Buckies. A Land Without Gods. Process Theory, Maldevelopment and the Mexican Nahuas. Londres y Nueva Jersey: Zed Books, 1995.

Del Ángel Perez, Ana. "Ganadería ejidal o satélite productivo de la ganadería privada”. En Agricultura y sociedad en México. Diversidad, enfoques, estudios de caso, comps. Alba González Jácome y Silvia del Amo Rodríguez, 267-283. México: uI, Gestión de Ecosistemas A. c., Plaza y Valdés, Consejo Nacional para la Enseñanza de la Biología A. C., 1999.

Delgado, Alfredo. "La conformación de regiones en el Sotavento veracruzano: una aproximación histórica". En El Sotavento veracruzano. Procesos sociales y dinámicas territoriales, coords. Eric Léonard y Emilia Velázquez, 27-41. México: Ciesas-IRD, 2000.

Guevara, Sergio. "Presentación". En Historia ambiental de la ganadería en México, comp. Lucina Hernández, 1-6. México: Instituto de Ecología, A. C., 2001.

LAzos, Elena. "La ganaderización de dos comunidades veracruzanas: condiciones de la difusión de un modelo agrario". En El ropaje de la tierra. Naturaleza y cultura en cinco zonas rurales, coords. Luisa Paré Quellet y Martha Judith Sánchez, 177-241. México: Plaza y Valdés, unAM, 1996. 
PARÉ, Luisa y otros. La reserva especial de la biosfera Sierra de Santa Marta, Veracruz: diagnóstico y perspectiva. Mexico: UnAM, SEMARNAT, 1997.

RoBles, Héctor. Los tratos agrarios, vía campesina de acceso a la tierra: la experiencia de San Idelfonso Tultepec. México: Cámara de Diputados Lix Legislatura, Secretaría de la Reforma Agraria, Centro de Estudios para el Desarrollo Sustentable y la Soberanía Alimentaria, 2005.

Rutsch, Mechthild. La ganadería capitalista en México. México: Editorial Línea, 1984.

Saucedo Montemayor, Pedro. Historia de la ganadería en México, tomo I. México: Unam, 1984.

Thompson, Guy P. C. "La colonización del departamento de Acayucan: 1824-1834". Historia Mexicana, núm. 94 (1994): 253-298.

VelázQuez, Emilia. Territorios fragmentados. Estado y comunidad indigena en el istmo veracruzano. México: Publicaciones de la Casa Chata, Ciesas, 2006.

. "El territorio de los popolucas de Soteapan, Veracruz: transformaciones en la organización y apropiación del espacio". Relaciones. Estudios de Historia y Sociedad, vol. xxII, núm. 87 (verano 2001): 17-47.

"Ganadería y poder político en la Sierra de Santa Marta". En El Sotavento veracruzano. Procesos sociales y dinámicas territoriales, coords. Eric Léonard y Emilia Velázquez, 111-127. México: Ciesas, IRD, 2000.

- "Política, ganadería y recursos naturales en el trópico húmedo veracruzano: el caso del municipio de Mecayapan". Relaciones. Estudios de Historia y Sociedad, vol. XII, núm. 50 (primavera 1992): 23-63.

Villafuerte, Daniel, María del Carmen García y Salvador Meza. La cuestión ganadera y la deforestación. Viejos y nuevos problemas en el trópico y Chiapas. Tuxtla Gutiérrez: Universidad de Ciencias y Artes del Estado de Chiapas, Centro de Estudios Superiores de México-Centroamérica, 1997. 